\title{
A Look of Cognitonics at the Role of Museums in Cognitive Engagement of the Adolescents and University Students
}

\author{
Olga S. Fomichova ${ }^{1}$, Vladimir A. Fomichov ${ }^{2}$, Svetlana M. Gordeeva ${ }^{3}$ \\ ${ }^{1}$ Division "Dialogue of Sciences" \\ State Budget Professional Educational Institution "Sparrow Hills" \\ Universitetsky prospect 5, 119296 Moscow, Russia \\ ${ }^{2}$ School of Business Informatics, Faculty of Business and Management \\ National Research University \\ Higher School of Economics, Kirpichnaya str. 33, 105187 Moscow, Russia \\ ${ }^{3}$ Department of Interiors Art Design \\ S. G. Stroganov Moscow State Art - Industrial Academy, Moscow, Russia \\ vfomichov@hse.ru,vfomichov@gmail.com
}

ABSTRACT: This paper pertains mainly to art cognitonics, it is a significant branch of cognitonics, or the science about the human being in the digital world. The first aim of the paper is to consider a way of achieving cognitive engagement of the adolescents and university students at lectures on art cognitonics. The central idea is to expand the conceptual universe of the learners by means of messages conveyed by outstanding canvases and sculptures. Art cognitonics changes the perception of a work of art by the beholder in comparison with the traditional approach. The second aim is to state a new conception of a sci-fi museum (a science fiction museum), this conception is underpinned by cognitonics. The principal idea of the new conception is the creation of a thought-provoking space aiming at stimulating the process of perception of the power of thought, regarding thought as a value.

Keywords: Digital Science, Cognitonics

Received: 18 October 2018, Revised 24 December 2018, Accepted 9 January 2018

(C) 2019 DLINE. All Rights Reserved

DOI: $10.6025 / \mathrm{jcl} / 2019 / 10 / 2 / 37-43$

\section{Introduction}

One of the basic ideas of cognitonics in the field of education is the idea of regarding thought as a value. Its essence is as follows. A child is aware of the fact that his/her ideas may be socially significant, i.e. a child may be appraised by the friends or adults for the originality and beauty of his/her ideas; moreover, a child appreciates the value of the thoughts of other persons $[1-6]$.

The next basic idea of cognitonics is as follows. The outstanding works of art (we consider here painting) are the results of looking by their creators for the answers to acute questions of their time. Very often, young people are looking for the answers to, in fact, the same questions but in modified forms corresponding to our time. That is why it would be very reasonable and very desirable to expand the conceptual universe of young people by means of including into it the messages conveyed by outstanding works of art. 
This idea was the starting point for formulating in [7] the proposal to develop a new branch of cognitonics - art cognitonics (AC). The principal objective of AC is tuning the cognitive-emotional sphere of the young children and adolescents with the help of well-known works of art. The goal is "to create a bright semantic trace in the world's conceptual picture of the learner corresponding to an idea explaining or illustrating a moral value, communicative situation, a situation of making a decision, cognitive process itself, the process of self-cognition and consideration, the seething cocktail of emotions, a way of viewing the world around, etc. Art cognitonics establishes the links between the objects, situations, processes, views of a person (a beholder) and the work of art that becomes a metaphor or a vivid illustration (vivid mental representation) of something the beholder is considering about" [7].

The first aim of this paper is to show (on a concrete theme of a lecture) how it is possible to inscribe the messages conveyed by the pictures into the world's conceptual picture of the young beholder - an adolescent or a university student. The next aim of the paper is to introduce an original conception of a science fiction museum (a sc-fi museum).

\section{A New Approach to the Idea of a Sci-fi Museum Under the Framework of Cognitonics}

The power of thought and the beauty of thought that introduces beauty into the world, transfigures the reality (poetry, music, etc.), making breakthrough (scientific research) is still not so easy to understand because of the gap between the moments of inspiration felt by the creator and the embodiment of that breakthrough in some real discovery.

Inspiration is defined by Oxford dictionary as the process of having one's mind or creative abilities stimulated, especially in art, music, or literature. Such notions are cultural assets, scientific assets are very often not easy to understand by the contemporaries, because the work of art or scientific research aiming at solving a scientific problem or constructing a theory, breaking fresh ground, suggests the changes in the conceptual picture of the world, turning the extra ordinary things into ordinary.

A museum is a building in which objects of artistic, cultural, historical or scientific interest are displayed. It is a public place for keeping the collections, studying them, and displaying them. The museums play an important role in socialization of the young generation and in the educational process in general.

A science fiction museum (sci-fi museum) might be a type of museum based on imagined scientific discoveries of the future being turned into a reality. The difference between the conception of a science museum and sci-fi museum is as follows. A science museum displays the achievements of the human society but a sci-fi museum displays the results of the so called cognitive experiment, on the one hand, or a scientific guess about the future, on the other hand.

There are examples of sci-fi museums such as Experience Music Project and Science Fiction Museum and Hall of Fame in Seattle. It was founded by Paul Gardner Allen, a cofounder of Microsoft (together with Bill Gates), and the producer Jodi Patton. The museum displays sci-fi books, journals, items of scenery from the Hollywood films, props. Such museums may include computer games, robots, etc.

A new approach to the idea of a sci-fi museum under the framework of cognitonics aims at focusing the attention on the power of thought, though-provoking books, and the look at the future. We are interested in such notions as hard science fiction. This notion was used for the first time by P. S. Miller in 1957 in his review published in the journal "Astounding Science Fiction". The ideas expressed in sci-fi were regarded as utopia at the time the book introduced these ideas was published. For example, the novels "Robur le Conquerant" and "Maitre du Monde" by Jules Gabriel Verne brought a helicopter and an airplane into being and were regarded as utopian ones.

Not only scientific breakthrough might be thrilling but also the considerations of the writers on the subject. For example, Philip Kindered Dick in his novel "Do Androids Dream of Electric Sheep?" (1968) puts the question were there is the end of the consideration and the beginning of a reflex; where the human being differs from the animals or from the robots, whether we have the right to distinguish ourselves from something that fulfils the same tasks but in another way.

Jules Gabriel Verne in the novel « Robur le Conquerant» in 1876 came to the conclusion that the success of science should not outstrip the improvements of spiritual maturity. Otherwise the science will become dangerous.

The main idea of a new conception of a sci-fi museum is the creation of a thought-provoking space aiming at stimulating the

$38 \quad$ International Journal of Computational Linguistics Research Volume 10 Number 2 June 2019 
process of perception of the power of thought, regarding thought as a value. It will help to better understand the variety of possibilities, to find a new look at the common things, and to be thrilled by the power of creativity and happiness of inspiration.

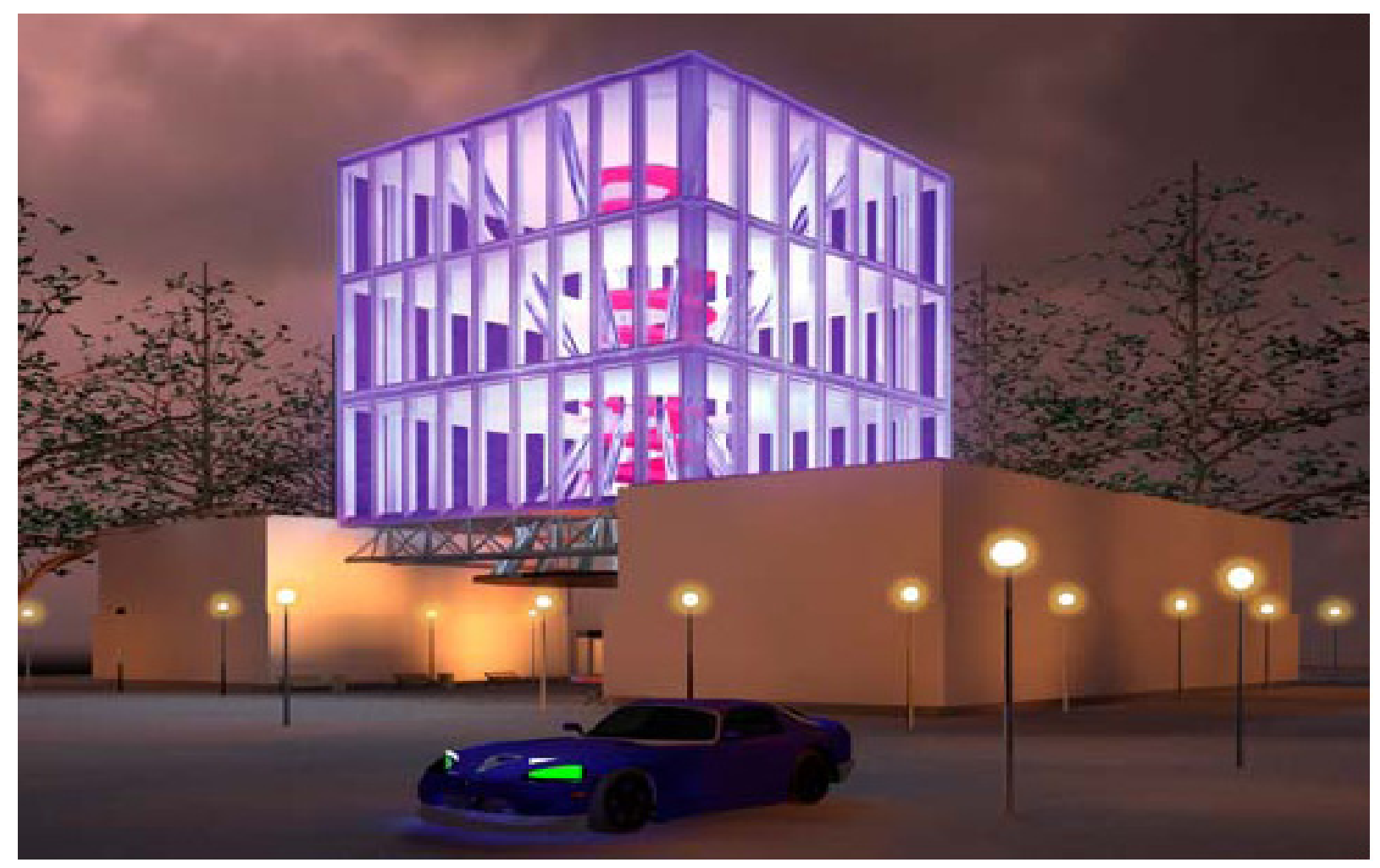

Figure 1. A view at the sc-fi museum in accordance with the suggested new conception (S. M. Gordeeva)a

The museum should encourage the belief in the power of thought, show the thought boundless space, paying a special attention to the responsibility for the ideas: humans should think and act in terms of public good and regard the home planet as their sweet home (see Figure 1). The museum might contain:

- A Permanent Display: It includes the items revealing the achievements of the humans in various scientific domains which completely changed the idea of people about the world and the power of thought, the examples of guesses, of the sci-fi writers about the future which were not recognized by the contemporaries and, as a result, were underestimated by the contemporaries;

- The Room of Models: The way humans imagine the things (technical objects, materials, etc.) in different periods of time; it might help to better understand (to observe) the development of science and technology; it is possible to display instruments, devices belonging to well known scientists;

-A Video Room: It makes it possible to show the films about the experience, about the evolution of the idea generation process;

-A Temporary Display: The objects from other museums and private collections;

- The interactive rooms;

- The demonstration rooms revealing a correspondence between the content of the sci-fi books and scientific achievements;

- A conference room;

- The lecture rooms;

- The rooms representing the modern view of the future, of future achievement, and possible kinds of breakthrough in various domains.

International Journal of Computational Linguistics Research Volume 10 Number 2 June 2019 


\section{Cognitive Engagement at the Lessons of Art}

Let's consider the way of achieving cognitive engagement and personal involvement of the students in the process of discussing the subject "The balance between privacy and the expressiveness of the portraits of the painter's wife". We understand privacy as the state of freedom from interference or public attention. On the other hand, expressiveness and vividness are the positive characteristics of the portrait. The problem is how to overcome this contradiction.

Cognitive engagement is defined in $[8,9]$ as the process of highly motivated intellectual activity when the interest towards the subject under discussion is so strong that the students loose the track of time and, as a result, they are not tired. The students' interest determines the level of involvement. The emotional response is very close to inspiration, because they are making their own discoveries, and their mental efforts are appreciated. It helps to provide a conceptual learning environment instead of a memorization based one and enhances the motivation. Cognitive engagement is created mainly by the components called in [8, 9] focused attention, positive effect, aesthetics, endurance, novelty, motivation.

The creation of focused attention is based on the contradiction between the idea of privacy, that is, as the state of freedom from interference or public attention, and expressiveness, that is, showing (revealing in the picture) one's feelings or thoughts. It evokes own feelings, brings a memory into student's mind. As a result, the students come to the conclusion "It is my cup of tea".

Positive effect has been achieved when students say "It is good for me". This conclusion is underpinned by their own reasoning: on the one hand, never let anyone trespasses onto my privacy; on the other hand, "I'd like to have my portrait painted, why not". It means that interest toward the subject under discussion is evoked because it is self-oriented.

Aesthetics suggests the answer to the question: how to make the way the material is presented meet the expectations of the students - to make the presented material personal. In this case, emotional response is more vivid and, consequently, intellectual response is more thought-provoking. Painting in general touches the heart, making us enjoy it; and then the viewer should understand that every work of art conveys the artistic (philosophical or any other) message.

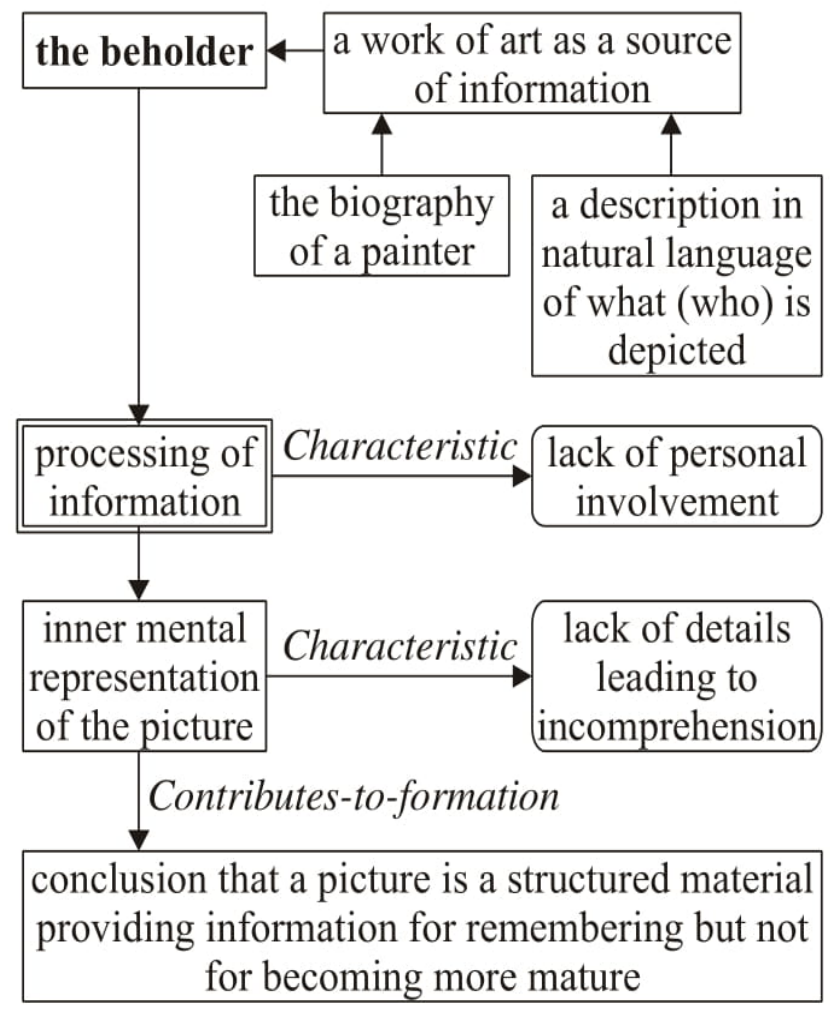

Figure 2. The traditional way of perceiving the painting 
Endurance means that a student remembers a good experience and wants to repeat it. The student keeps turning over the picture in his/her mind, trying to have another look at his/her own private relationships.

Novelty is to be presented at every lesson for providing intellectual and spiritual nourishment. The described lecture considers four portraits: the portrait of the wife by Michael Vrubel ("After the concert", 1905), the portrait of the wife by Ilya Repin ("The Rest", 1882), the portrait of the wife by Marc Chagall ("The Walk", 1917 -1918), the portrait of the wife by Petrov-Vodkin ("The portrait of the painter's wife", 1906). The pictures show a great delicacy and tact, love and tenderness, inspiration, beauty, nobility, dignity, romance, and sexuality. The portrait is a reflection of the sitter in the eyes of the painter, in our case, the reflection of the wife, the muse in the eyes of the husband. It always leads to consideration, objection, admiration, hesitation on the part of the students. In all cases, the level of relationships revealed on the canvas is much higher than that most students get accustomed too. The process of involving the students into a discussion helps to better understand the language of painting, on the one hand, and to start considering the model of relationships with their beloved. It starts up the creative process in the heads of the students, giving them the opportunity for the most effective knowledge acquisition, information processing, etc.

Usually motivation of the students is closely connected with their values. Everyone answers the question: "What is good for me and how to achieve the state of complete happiness ?". The question under discussion influences the system of values, on the one hand, and reveals it, on the other hand. It is a good example how to make students be interested in art, because art is always provocative and makes them gain an insight into a problem of personal relationships, a loving or sexual association between two people. This lecture on painting is an example of creative environment of conceptual learning instead of a memorization-based one.

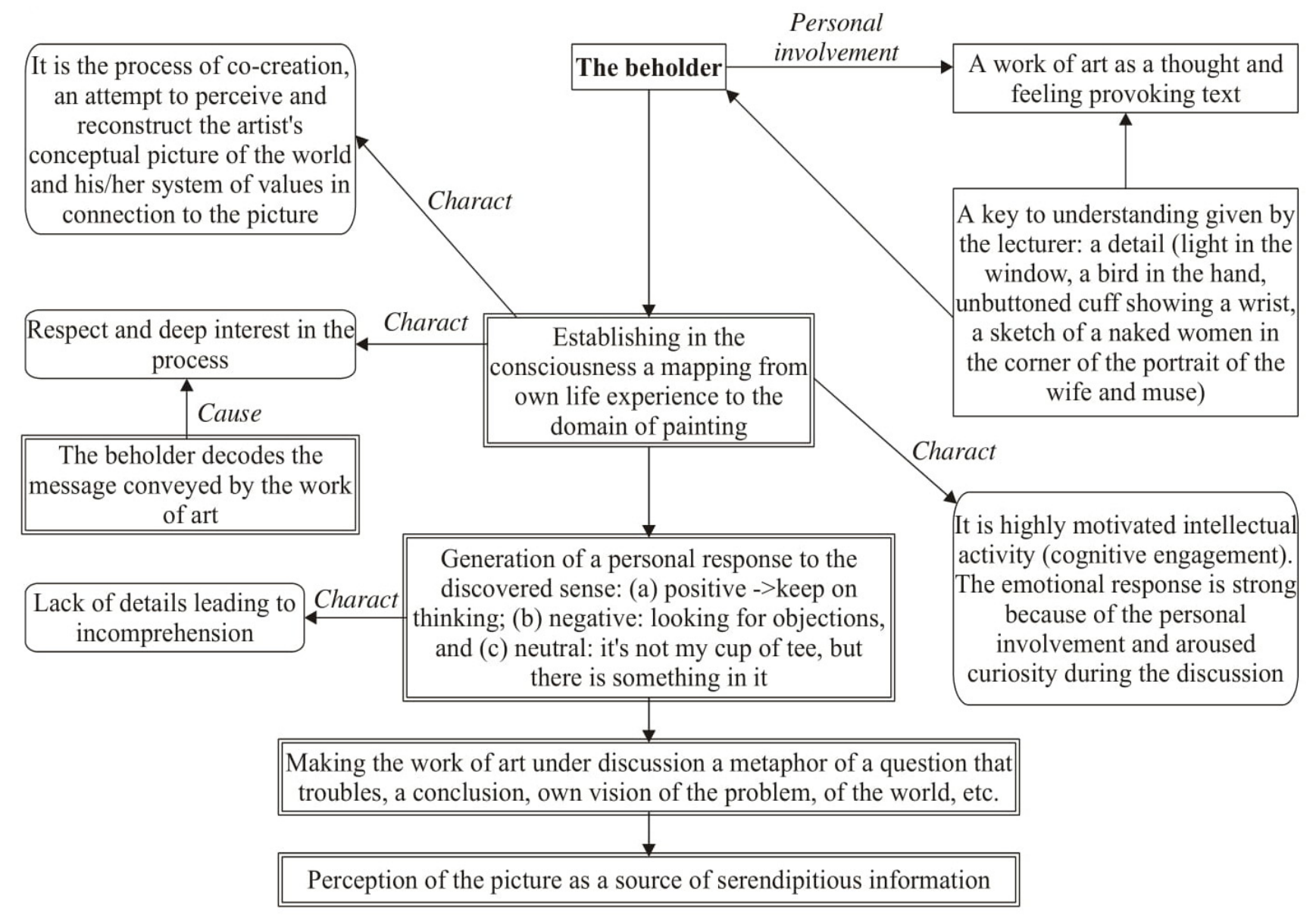

Figure 3. The way cognitonics changes the perception of a work of art ("Charact" - "Characteristic") 
The focus of the lecture is paying attention to the key details in the pictures, such as an unbuttoned cuff showing a wrist (Repin), a sketch of a naked women on the portrait of the wife (Petrov-Vodkin), unfinished portrait of the wife after a concert in a relaxing pose when the tide face is not clearly seen (Vrubel), the flying woman in the blueness of the sky, spirited, adored by her husband who holds her by the hand (Chagall). The lecture establishes in the consciousness of the student a mapping from the objects and situations, relationships existing in their life to the domain of language of painting, on the one hand, and relationships between two beloved, on the other hand. That is why the consciousness of the students receives a considerable impulse to developing the ability of establishing diverse analogies.

\section{Conclusion}

The paper grounds the necessity of a new look at the power of thought under the framework of art cognitonics. The paper sets forth a new way of representing painting to the students, making them step by step come to the idea of serendipitous information which is not expected but desirable and conduces to making their own discoveries in painting. Thus painting becomes the way of expressing one's views and makes the world of the students much broader, much more emotional and metaphoric.

The paper gives an example of achieving cognitive engagement of the students at the lessons of art. It shows how to provide the conceptual learning environment instead of a memorization-based one and enhances the motivation to regard the pictures of Russian painters Repin, Vrubel, Chagall, Petrov-Vodkin.

The paper suggests a new conception of a science-fiction museum under the framework of cognitonics. This conception is underpinned by the ideas of making thought visible and the processing of thinking - thrilling and vivid to promote the idea of positively oriented creativity and make thinking in vogue.

\section{Acknowledgement}

We are grateful to the senior software specialist Alexander Artyomov who kindly helped us to prepare electronic versions of the figures 2 and 3.

\section{References}

[1] Fomichov, V. A., Fomichova, O. S. (2000). The Social Responsibility of Computer Science Specialists for the Creative Potential of the Young Generation. International Journal of Artificial Intelligence in Education 11. p. 208- 219.

[2] Fomichova, O., Fomichov. V. (2000). Computers and the Thought-Producing Self of the Young Child. The British Journal of Educational Technology 31. p. 213-220. 2000.

[3] Fomichova, O. S. (2001). A Principal Cognitive Precondition of Successful Child-Computer Interactions in the Information Society. Special Issue "Developing Creativity and Large Mental Outlook in the Computer Age, Educational Technology and Society 4.p. 41-47.2001.

[4] Fomichov, V. A., Fomichova, O. S. (2011). A Map of Cognitive Transformations Realized for Early Socialization of Children in the Internet Age. In: M. Bohanec, M. Gams et al (Eds.). Proceedings of the 14th International Multiconference Information Society - IS 2011, Volume A. Slovenia, Ljubljana, Jozef Stefan Institute; http://is.ijs.si/is/is2011/zborniki.asp?lang=eng; pp. 353357.

[5] Fomichov, V. A., Fomichova, O. S. (2012). A Contribution of Cognitonics to Secure Living in Information Society. Informatica. An International Journal of Computing and Informatics (Slovenia) 36. p. 121-130. .

[6] Fomichov, V. A. (2015). Conscious Control during Childhood, Development of. In: James D. Wright (editor-in-chief). International Encyclopedia of the Social and Behavioral Sciences, 2nd edition, Vol. 4. Oxford: Elsevier. p. 666- 672.

[7] Fomichov, V. A., Fomichova, O. S. (2015). Early Development of the Human Being Ideal Constituent and Art Cognitonics as the Answer to the Challenge of Knowledge Society. In: Proc. $18^{\text {th }}$ Int. Multiconference Information Society - IS 2015, Volume “Conference Kognitonika/Cognitonics". Slovenia, Ljubljana, Jozef Stefan Institute, 12 - 13 October 2015. .2015.

[8] Fomichova, O. S.,Fomichov, V. A. (2013). The Risk of Postponing Early Socialization of Smart Young Generation in Modern Information Society. In: M. Gams, R. Piltaver, D. Mladenic et al (Eds.), Proceedings of the 16th International Multiconference 
Information Society - IS 2013, Slovenia, Ljubljana, 7 - 11 October 2013. Vol. A. The Conference Kognitonika/Cognitonics. Jozef Stefan Institute. 2013, p. 430-434; http://is.ijs.si/is/is2013/zborniki.asp?lang=eng. 2013.

[9] Fomichov, V., Fomichova, O. (2015). An Imperative of a Poorly Recognized Existential Risk: Early Socialization of Smart Young Generation in Information Society. Informatica. An International Journal of Computing and Informatics (Slovenia) 38. p. 59-70. 2014. 